\title{
HDA cycloadditions of 1-diethoxyphosphonyl-1,3-butadiene with nitroso heterodienophiles: A computational investigation
}

\author{
Jean-Christophe Monbaliu $^{\mathrm{a}, *}$, Georges Dive ${ }^{\mathrm{b}}$, Jacqueline Marchand-Brynaert ${ }^{\mathrm{a}}$, Daniel Peeters ${ }^{\mathrm{a}}$ \\ a Institute of Condensed Matter and Nanosciences, IMCN/MOST, Université catholique de Louvain, Pl. Louis Pasteur 1, B-1348 Louvain-la-Neuve, Belgium \\ ${ }^{\mathrm{b}}$ Centre d'ingénierie des protéines, Institut de Chimie, Université de Liège, Bâtiment B.6, B-4000 Sart Tilman, Liège, Belgium
}

\section{A R T I C L E I N F O}

\section{Article history:}

Received 15 June 2010

Received in revised form 5 August 2010

Accepted 8 August 2010

Available online 12 August 2010

\section{Keywords:}

DFT

Cycloadditions

Polar Diels-Alder

Reaction mechanisms

Phosphonodiene

Heterodienophiles

\begin{abstract}
A B S T R A C T
The hetero Diels-Alder (HDA) reactions of 1-diethoxyphosphonyl-1,3-butadiene with various nitroso dienophiles have been studied at the B3LYP/6-31G** level. Structural, energetic and electronic properties are discussed. These cycloadditions with nitroso dienophiles are characterized by a total proximal regioselectivity and an endo selectivity. The influence of the nitroso substitution on the activation barrier and the regiochemistry of the reaction is presented. The analysis of the chemical rearrangement along the intrinsic reaction pathway (IRC), based on bond order and on natural bond orbital (NBO) calculations, emphasizes the polar nature of these cycloadditions. Despite the early and the cyclic nature of the corresponding transition states, a two-center interaction governs this mechanism: these cycloadditions are Polar Diels-Alder reactions (P-DA).
\end{abstract}

(C) 2010 Elsevier B.V. All rights reserved.

\section{Introduction}

The hetero Diels-Alder (HDA) reaction is a powerful tool used to build up six-membered heterocycles in one convergent step [1]. By contrast to the typical Diels-Alder reaction, at least one of the six reacting carbons is replaced by a heteroatom (mainly oxygen, nitrogen or sulfur) [2]. Among these reactions, HDA reactions of nitroso compounds have been studied as an entry towards aza-heterocycles $[2,3]$. Depending on their substitution, the nitroso derivatives can be considered as heterodienes or heterodienophiles. Less attention is dedicated to the former as a consequence of their instability and high reactivity [4]. Contrastingly, the nitroso dienophiles are recognized as useful partners for HDA reactions even cycloadding with low activated dienes. Several computational studies have been dedicated to nitroso HDA reactions in order to predict their regioselectivity [5]. Among these, a study by Leach and Houk provides some rules [5a]. This study focuses on some model nitroso dienophiles and a set of representative dienes. Its conclusion is that the regiochemistry mainly results from the diene substitution (both the position and the nature of the substituent). The experimental data from the literature reinforce the driving effect of the diene substitution (Fig. 1): the lower the diene activa-

\footnotetext{
* Corresponding author. Present address: Research Group SynbioC, Department of Sustainable Organic Chemistry and Technology, Faculty of Bioscience Engineering, Ghent University, Coupure Links 653, B-9000 Ghent, Belgium. Tel.: +32 9 2645860; fax: +32 92646243.

E-mail address: jeanchristophe.monbaliu@ugent.be (J.-C. Monbaliu).
}

tion, the lower the regioselectivity. In this case, the reaction leads often to a mixture of the proximal and distal regiosomers [6].

Among the low activated butadienyl compounds, dienes possessing a dialkoxyphosphonyl moiety in 1-position (e.g. diene 1a) are known to display poor reactivity in Diels-Alder (DA) reactions [7]. The slight phosphonate activation of the butadienyl system proceeds by partial polarization [8], in a very different way of the widely illustrated $\alpha$-negative charge stabilization [9]. Their cycloadditions with classical dienophiles have been studied in the past [8a], but there is no data concerning their nitroso HDA cycloadditions.

Accordingly, the expected regioselectivity for the reaction of 1a with a nitroso dienophile should be low. This is in contradiction with a recently reported example of a regioselective and efficient HDA cycloaddition of diene 1a with 2-nitrosotoluene (2b) (Fig. 2) [10a]. This opens the way towards the synthesis of aliphatic and alicyclic aminophosphonic compounds $[10,11]$. In such a strategy, the regiochemical outcome of the key HDA reaction has a drastic incidence on the whole efficiency.

The present study aims to provide quantitative information and mechanism insights regarding the HDA reactions of 1-diethoxyphosphonyl-1,3-butadiene (1a) and a model (2a) or nitroso dienophiles of potential synthetic interest $(\mathbf{2} \mathbf{b}-\mathbf{g})$. In particular, the reaction mechanism and the implication of the phosphonate in the proximal regioselectivity will be investigated. For that purpose, the results obtained for diene 1a will be compared with classical dienes both activated $(\mathbf{1} \mathbf{b}, \mathbf{c})$ or not (butadiene, etc.). The governing 


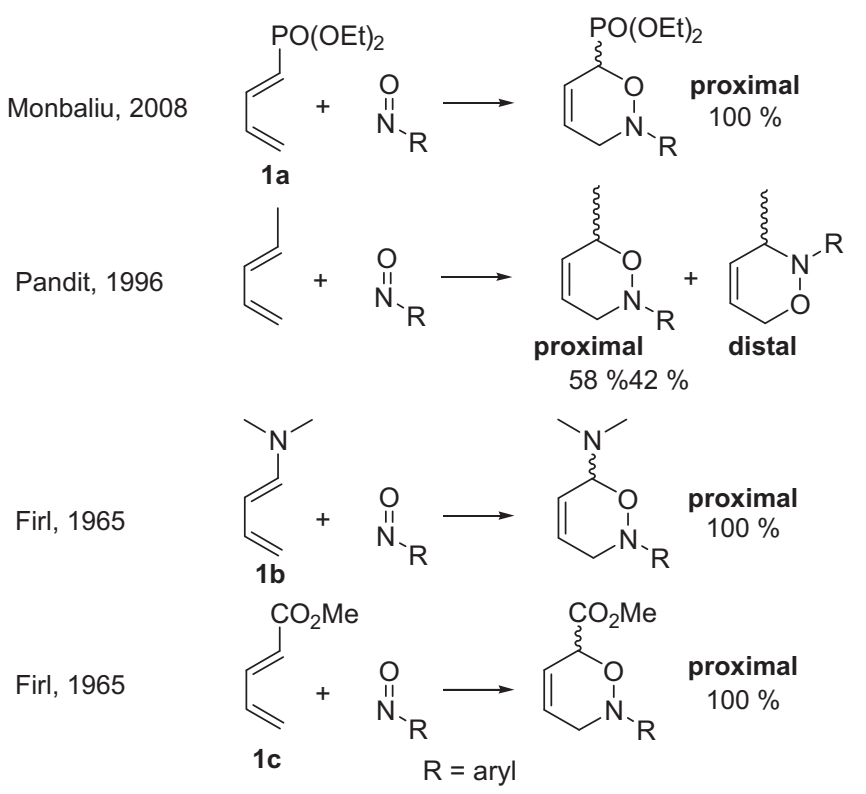

Fig. 1. Experimental regioselectivities.

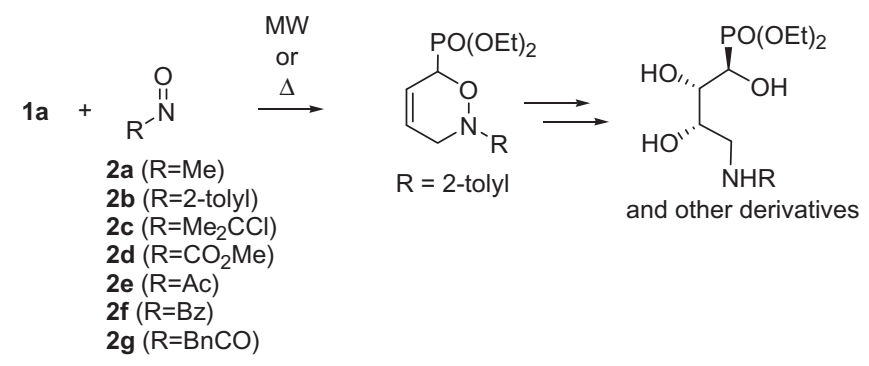

Fig. 2. HDA cycloadditions of diene 1a and nitroso dienophiles 2a-g.

parameters will be determined at the B3LYP/6-31G** level. A kinetic study $(\mathbf{1} \mathbf{a}+\mathbf{2 b})$ is presented. A global electrophilicity index is used to classify the dienophiles according to their intrinsic reactivity.

\section{Methodology}

All calculations are performed with the density functional theory (DFT) using the B3LYP[12] functional with the GAUSSIAN 98 series of programs [13]. The Pople $6-31 G^{* *}$ double zeta polarized basis set is selected [14]. The analytical second derivatives are used to determine the nature of the stationary points. The Intrinsic Reaction Coordinate (IRC) [15] has been followed for a few representative cases. A Natural Bond Orbital (NBO) analysis brings some further insight on the electronic structure and charge distribution $[16,17]$.

A question often raised by experimentalists concerns bond formation and synchronicity $\left(S_{y}\right)$. For a Diels-Alder reaction, the synchronicity is defined as the relative extend of bond breaking and making process. This concept is in general only qualitatively descriptive. A way to have a more quantitative definition of the synchronicity requires Wiberg's indexes and bond order calculations using the procedure introduced by Moyano and co-workers [17a]. According to this procedure, reactions could be classified on the synchronicity scale: from stepwise mechanisms $\left(S_{y}=0\right)$ to concerted synchronous mechanisms $\left(S_{y}=1\right)$.
Several theoretical studies, particularly in the field of cycloaddition reactions, have shown that the analysis of reactivity indexes defined within DFT at the ground state of the reagents are able to furnish information about the reactivity [18]. These indices are based on the HSAB theory extended to global properties. The electrophilicity index $(\omega)$ measures the capability of a molecule to accept electrons. It has been defined in terms of static global properties, namely chemical potential $(\mu)$ and chemical hardness $(\eta)$. This global electrophilicity index is calculated by the procedure introduced by Domingo [19,20].

\section{Results and discussion}

\subsection{Model HDA reaction with nitrosomethane (2a)}

Nitrosomethane (MeNO, 2a) is selected as a model hetero dienophile for a preliminary investigation. Its cycloaddition onto phosphonodiene 1a is computed (Fig. 3) to establish the general features of this HDA reaction. The most relevant results are discussed here, related to the most stable conformer of diene 1a, i.e. with the $\mathrm{P}=\mathrm{O}$ in syn conformation to the butadienyl moiety.

Considering the structures of $\mathbf{2 a}$ (MeNO), the diene $\mathbf{1 a}$ and the cycloaddition products (4p,d in Fig. 3), overall energy changes of $23 \mathrm{kcal} \mathrm{mol}^{-1}$ for the proximal adduct and $19 \mathrm{kcal} \mathrm{mol}^{-1}$ for the distal one are calculated. There are only two cycloadducts (4p,d) to be expected from this reaction, despite the fact that endo/exo transition states (TSs) are isolated for each regioisomeric pathway. These TSs are labelled TS1pn, TS1px, TS1dn and TS1dx. Where p, d stand for proximal and distal and $\mathbf{n}, \mathbf{x}$ are relative to endo/exo approaches (Fig. 3).

The results from Fig. 3 indicate that the activation barrier for TS1 pn is the lowest. The stereoselectivity, given by the relative energy between the exo TS and its endo counterpart, shows that the exo TS is disfavoured over the endo one by some $2.7-7.1 \mathrm{kcal} \mathrm{mol}^{-1}$. This feature retrieves the conclusions of Leach and Houk for other systems and is attributed to the "exo lone pair" effect [5a]. Similar stereoselectivities are computed for butadiene or piperylene (6.7$6.8 \mathrm{kcal} \mathrm{mol}^{-1}$, Fig. 4) leading to conclude that the phosphonate moiety does not induce a specific stereoselectivity.

Further on, the regioselectivity $\left(\Delta \Delta E^{\neq}\right)$can be expressed by the energy differences between the two lowest TSs on each regioisomeric channel, namely TS1pn and TS1dn (Fig. 3 and Table 1). In order to obtain more information concerning the phosphonate effect on the regioselectivity, these values have been compared with the activation barriers for the HDA reactions of other dienes with nitrosomethane (2a, Table 1). As expected, the effect of the phosphonate moiety on the activation barrier is low (entries 1-4). Contrastingly, activated dienes such as $(E)-\mathrm{N}, \mathrm{N}$-dimethylbuta-1,3dien-1-amine (1b) or (E)-methyl penta-2,4-dienoate (1c) show significant activation effect on this HDA reaction (entries 5-6). Another interesting observation is the emergence of a proximal regioselectivity for diene $\mathbf{1 a}$, that is not observed for piperylene (Table 1, entry 3 ). The computed regiodiscrimination for diene 1a ( $5.8 \mathrm{kcal} \mathrm{mol}^{-1}$ in favour of the proximal adduct) is 15 times higher than for piperylene.

From the structural point of view, the $\mathrm{N}_{5}-\mathrm{C}_{4,1}$ bond shows significant formation compared to the $\mathrm{O}_{6}-\mathrm{C}_{1,4}$ bond, whatever the proximal or distal channel. Geometrically, these TSs are similar to those obtained for butadiene and piperylene (TS2n, TS2x, TS3pn and TS3px in Fig. 4). The $\mathrm{C}_{4}-\mathrm{N}_{5}$ bond length is close to the $\mathrm{C}-\mathrm{N}$ bond in the proximal cycloadduct $\left(1.46 \AA\right.$ ) while the $\mathrm{C}_{1}-\mathrm{O}_{6}$ bond remains closer to the sum of the Van der Waals radii for $\mathrm{C}$ and $\mathrm{O}$ $(3.24 \AA)$ than to the final length in the proximal cycloadduct (1.44 $\AA$ ). This is similar to the situation described by Leach and Houk for the reaction of butadiene and HNO. These authors have 


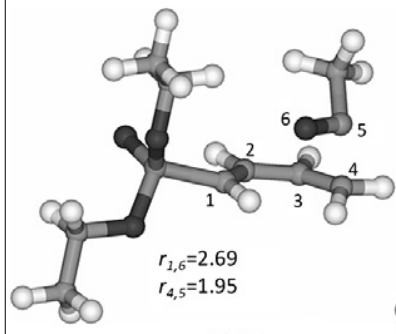

TS1pn
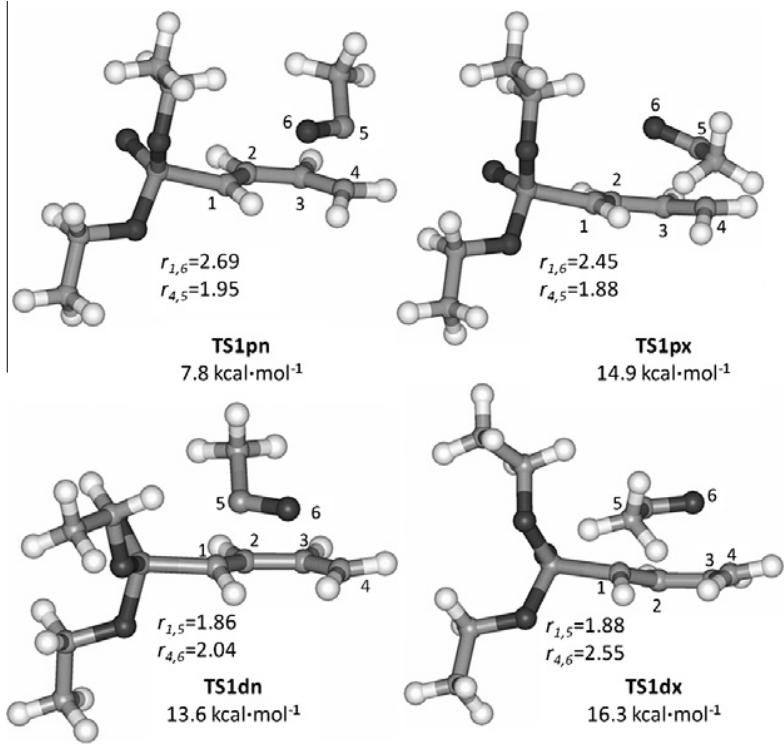

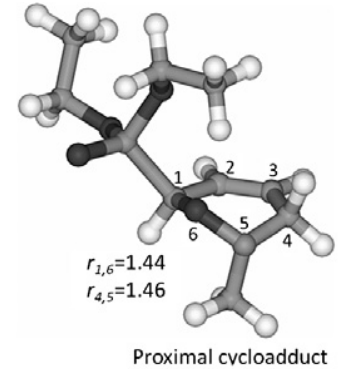

$(4 p)$

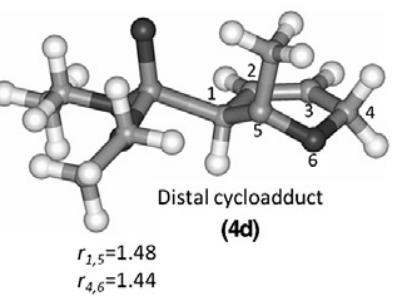

Fig. 3. B $3 L Y P / 6-31 G^{* *}$ structures of the transition states for $\mathbf{1 a}+$ MeNO and of the proximal or distal cyclodducts (4p,d).

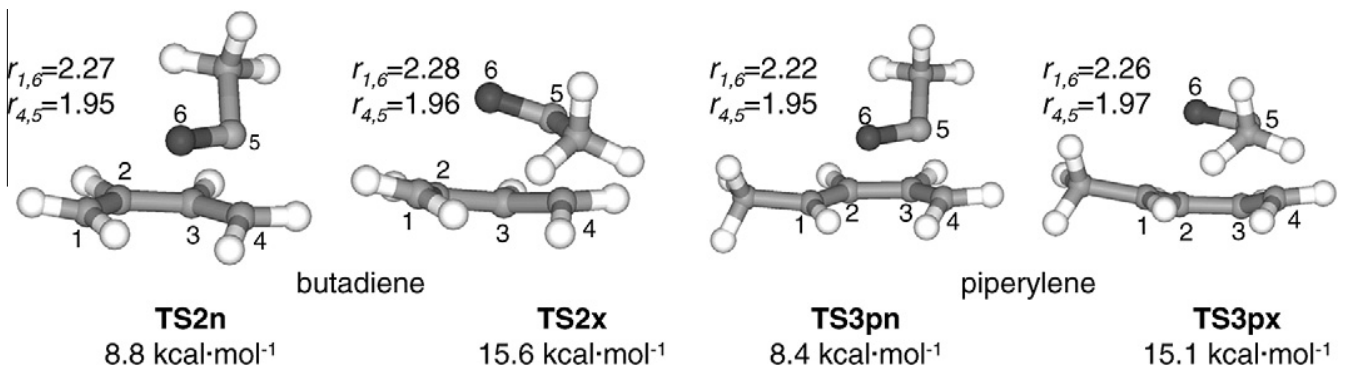

Fig. 4. Transition states for butadiene and piperylene + MeNO.

Table 1

Computed activation barriers $\left(\Delta E^{\neq}\right)$and regiodiscrimination $\left(\Delta \Delta E^{\neq}\right)$for the HDA cycloaddition of representative dienes + MeNO (computed at $0 \mathrm{~K}$ fixed nuclei).

\begin{tabular}{lllll}
\hline \multirow{2}{*}{ Entry } & Diene & \multicolumn{2}{c}{$\Delta E^{\neq}\left(\mathrm{kcal} \mathrm{mol}^{-1}\right)$} & \multirow{2}{*}{$\Delta \Delta E^{\neq}$} \\
\cline { 3 - 3 } & & Proximal & Distal & \\
\hline 1 & Butadiene & 8.8 & $/$ & $/$ \\
2 & Cyclo-pentadiene & 9.6 & $/$ & $/$ \\
3 & Piperylene & 8.4 & 8.8 & 0.4 \\
4 & 1a & 7.8 & 13.6 & 5.8 \\
5 & 1b & 2.7 & 11.2 & 8.5 \\
6 & 1c & 5.9 & 9.1 & 3.2 \\
\hline
\end{tabular}

concluded that a concerted very asynchronous TS for the cycloaddition HNO + butadiene may link the starting material to an "intermediate" in which the $\mathrm{C}-\mathrm{N}$ bond is fully formed but with negligible formation of the $\mathrm{C}-\mathrm{O}$ bond [5a]. This feature is named one-step two-stage by Domingo and is a characteristic of Polar Diels-Alder reactions (P-DA) [20]. Indeed, in this present case, an IRC analysis performed for the most favourable proximal pathway emphasises this two-center interaction: after a fall of about $6 \mathrm{kcal} \mathrm{mol}^{-1}$, the reaction path reaches a flat region of the energy surface in which the $\mathrm{C}_{4}-\mathrm{N}_{5}$ bond length is about $1.51 \AA$ and $\mathrm{C}_{1}-\mathrm{O}_{6}$ length equals $2.55 \AA$.

The $i$ calculated bond orders $\left(B_{i}\right)$ for reactants, TS and products enabled the detailed examination of the progress of the bond making and breaking processes at the TS. The analysis of $B_{i}$ of the proximal TSs indicates more progress in $C_{3}-C_{4}$ bond (53-60\%) while the changes in $\mathrm{C}_{4}-\mathrm{N}_{5}$ are intermediate in the reaction coordinate (43-52\%). Less progress is observed in $\mathrm{C}_{1}-\mathrm{C}_{2}, \mathrm{C}_{2}-\mathrm{C}_{3}, \mathrm{~N}_{5}-\mathrm{O}_{6}$ and $\mathrm{O}_{6}-\mathrm{C}_{1}$.

The calculated synchronicity values $\left(S_{y}\right)$ are consistent with a polar transition state $\left(S_{y}=0.75-0.94\right)$. Comparison with $S_{y}$ values computed for piperylene and butadiene $\left(S_{y}=0.76\right.$ or 0.9 for endo or exo approach, respectively) demonstrate that this asynchronicity in bond formation arises from the nitroso asymmetric nature. Finally, computed average values for the global bond reorganisation in the TS of $38 \%$ is compatible with reactant-like (or precocious) TS in accordance with Hammond's postulate.

To summarize, the HDA reaction between MeNO (2a) and 1diethoxyphosphonyl-1,3-butadiene (1a) proceeds via a one-step two-stage mechanism, governed by a two-center interaction $\left(\mathrm{N}_{5}-\mathrm{C}_{4}\right)$. The phosphonate moiety induces proximal regio- discrimination.

\subsection{The case of 2-nitrosotoluene (2b)}

Computed $S_{y}(0.73-0.77)$ and IRC reaction profiles are consistent with the model of reactivity developed above: the cycloaddition of $\mathbf{1 a}$ and nitrosotoluene ( $\mathbf{2} \mathbf{b})$ proceeds via a one step two-stage mechanism (P-DA). In this section, the discussion will be focused on the most favourable TSs of each proximal and distal channels (TS5pn and TS5dn, Fig. 5). For the reaction of diene 1a and nitrosotoluene, overall energy changes of $17 \mathrm{kcal} \mathrm{mol}^{-1}$ for the most favoured proximal approach and $14 \mathrm{kcal} \mathrm{mol}^{-1}$ for the distal one 

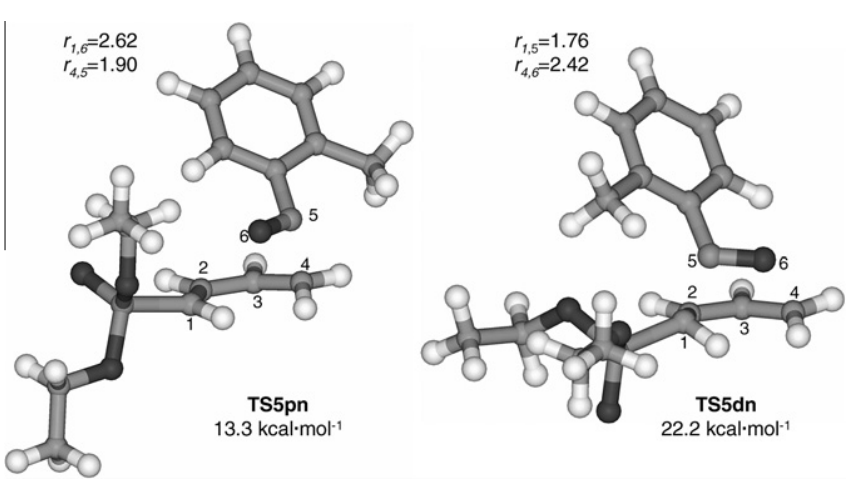

Fig. 5. Proximal and distal structures of the TSs for the reaction $\mathbf{1 a}+\mathbf{2 b}$.

were computed. Analysis of the TSs shows that the P-C free bond rotation can diminish but not compensate, the defavourable steric interaction between the nitroso substituent and the phosphonate moiety.

These computations (Fig. 5) predict large energetic differences in favour to the proximal TS $\left(\Delta E^{f}=13.3 \mathrm{kcal} \mathrm{mol}^{-1}\right)$ compared to the more hindered distal $\left(\Delta E^{f}=22.2 \mathrm{kcal} \cdot \mathrm{mol}^{-1}\right)$, in agreement with the experimental proximal selectivity [10a]. Thermochemistry computed at $298.2 \mathrm{~K}$ for the most favourable TS5pn furnishes the enthalpy $\left(\Delta H^{\neq}=13.5 \mathrm{kcal} \cdot \mathrm{mol}^{-1}\right)$, the Gibbs' free energy $\left(\Delta G^{\neq}=21.0 \mathrm{kcal} \cdot \mathrm{mol}^{-1}\right)$ and entropy of activation $\left(\Delta S^{\neq}=-25.0\right.$ $\left.\mathrm{cal} \cdot \mathrm{mol}^{-1} \cdot \mathrm{K}^{-1}\right)$. The computed activation energy $\left(E^{\neq}\right.$a $)$is 14.7 $\mathrm{kcal} \cdot \mathrm{mol}^{-1}$.

Single point calculations have been carried out using the SCRF method implemented in Jaguar [21]. A dielectric constant of 4.9 or 37.5 and a solvent probe radius of 2.51 or $2.18 \AA$ for chloroform and acetonitrile were used. Results indicate comparable activation barriers of $12 \mathrm{kcal} \cdot \mathrm{mol}^{-1}$ and highlight a low sensitivity of this reaction towards solvent polarity (see Table 2 ). The computed regiodiscrimination in solvent is about $11 \mathrm{kcal} \cdot \mathrm{mol}^{-1}$ in favour of the proximal regioisomer, suggesting that no modification of the regioselectivity will occur in more polar solvents.

\subsection{The kinetic point of view}

This section is dedicated to the analysis of kinetic experimental data. The cycloaddition of nitrosotoluene (2b) onto 1-diethoxyphosphonyl-1,3-butadiene (1a) is completed within $10 \mathrm{~h}$ in refluxing dichloroethane and leads regioselectively to the proximal isomer $\mathbf{4 p}$. The kinetics of the HDA reaction $\mathbf{1 a}+\mathbf{2 b}$ are measured to obtain quantitative information. The reaction rate is monitored by ${ }^{1} \mathrm{H}$ NMR $500 \mathrm{MHz}$ spectroscopy and kinetics data in chloroform- $d$ are measured at $20,37,47$ and $67^{\circ} \mathrm{C}$ by collecting 600 experimental points. Equimolar solutions of $\mathbf{1 a}$ and $\mathbf{2 b}$ in sealed NMR tubes were submitted to a thermostated $500 \mathrm{MHz}$ spectrometer at the desired temperature. For each sample, the spectrometer was programmed to take a spectrum every $2.5 \mathrm{~min}$. A good linear second order plot is obtained in any case. Quantitative data about the activation parameters of this reaction are determined by calculating the temperature dependence of $k_{2}$ (see Fig. 6).

The Arrhenius activation parameter $\left(E_{\mathrm{a}} \neq=14.5 \mathrm{kcal} \cdot \mathrm{mol}^{-1}\right.$; $\ln A=14.7)$ as well as the enthalpy $\left(\Delta H^{\neq}=13.9 \mathrm{kcal} \cdot \mathrm{mol}^{-1}\right)$, the Gibbs' free energy $\left(\Delta G^{f}=23.1 \mathrm{kcal} \cdot \mathrm{mol}^{-1}\right)$ and entropy of activa-

\section{Table 2}

Computed activation barriers $\left(\mathrm{kcal} \mathrm{mol}^{-1}\right)$ in solvent phase for $\mathbf{1 a}+\mathbf{2} \mathbf{b}$.

\begin{tabular}{llll}
\hline & Gas & $\mathrm{MeCN}$ & $\mathrm{CHCl}_{3}$ \\
\hline$\Delta E^{\neq}$ & 13.3 & 12.1 & 12.2 \\
\hline
\end{tabular}

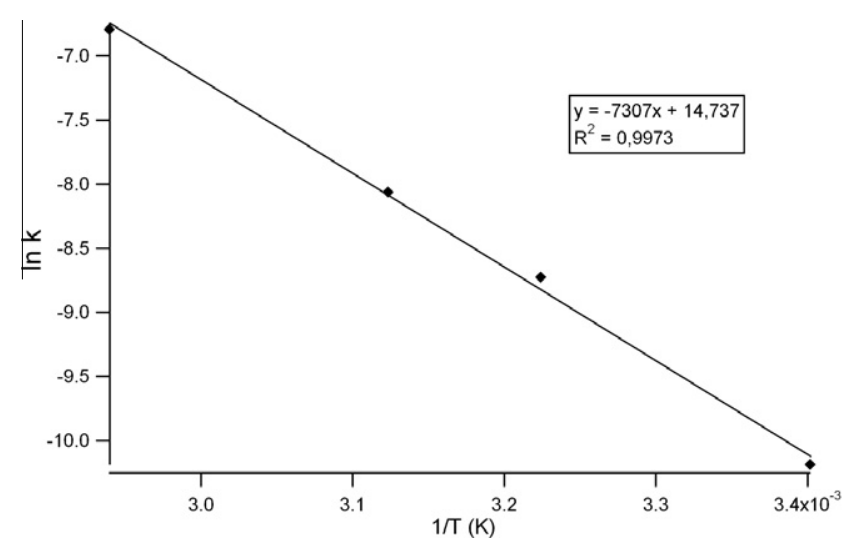

Fig. 6. Arrhenius plot. The $k_{2}$ values were measured at $20^{\circ} \mathrm{C}, 37^{\circ} \mathrm{C}, 47^{\circ} \mathrm{C}$ and $67{ }^{\circ} \mathrm{C}$ ([diene $]_{0}=[\text { dienophile }]_{0}=0.34-0.37 \mathrm{M}$ ) by $500 \mathrm{MHz}{ }^{1} \mathrm{H}$ NMR spectroscopy in $\mathrm{CDCl}_{3}$.

Table 3

Experimental second order rate constants for HDA reaction of $\mathbf{1 a}+\mathbf{2 b}$.

\begin{tabular}{lll}
\hline Solvent & $k_{2}^{\mathrm{a}}\left(\mathrm{M}^{-1} \cdot \mathrm{s}^{-1}\right)$ & Relative rates \\
\hline $\mathrm{CDCl}_{3}$ & $1.6 \times 10^{-4}$ & 1.0 \\
$\mathrm{CD}_{3} \mathrm{CN}$ & $2.3 \times 10^{-4}$ & 1.4 \\
\hline
\end{tabular}

a Experimentally determined at $37^{\circ} \mathrm{C}$ by $500 \mathrm{MHz}{ }^{1} \mathrm{H}$ NMR spectroscopy.

tion $\left(\Delta S^{\neq}=-31.0 \mathrm{cal} \cdot \mathrm{mol}^{-1} \cdot \mathrm{K}^{-1}\right)$ are obtained. These activation parameters are in good agreement with those obtained from the computations. The negative activation entropy value is characteristic for a highly ordered (cyclic) transition state, which is expected for a one step DA reaction. Also, the relatively small value of activation enthalpy leads to the same conclusion. A second solvent, acetonitrile- $d 3$, was used to estimate the sensitivity of this reaction $(\mathbf{1} \mathbf{a}+\mathbf{2 b})$ to the medium polarity. The second order rates $\left(k_{2}\right)$ are collected in Table 3 . The change from chloroform- $d$ to the more polar acetonitrile- $d 3$ leads to a 1.4 -fold increase of reaction rate. This moderate solvent effect is consistent with the low solvent dependence of one step DA reactions, as described in the literature [22].

\subsection{Extension to other nitroso dienophiles $(2 c-g)$}

The activation barriers for the cycloadditions of $\mathbf{1 a}$ and some representative nitroso compounds $(\mathbf{2 c - g})$ have been computed looking for structure-activity relationships and predicted regioselectivities. Some selected nitroso dienophiles of synthetic interest [23] (Fig. 7) are chosen. Experimentally, no cycloadducts are isolated from the reaction of dienophiles $\mathbf{2 d - g}$ and diene $\mathbf{1 a}$ under classical conditions. Nevertheless, these nitroso dienophiles are well known to be particularly reactive towards cyclohexadiene or cyclopentadiene, for example. Thus, the particularly low calculated activation barriers have to be related to the a priori selection of a cisoid conformer, which may be experimentally generated by addition of a coreactant such as 9,10-dimethylanthracene. The role of this coreactant has been discussed previously [24].

Fig. 7 indicates that the nitroso dienophiles reactivity towards diene $\mathbf{1 a}$ increases from nitrosotoluene $\mathbf{2 b}$ and $\boldsymbol{\alpha}$-chloro nitroso $\mathbf{2 c}$ to acyl nitroso compounds $\mathbf{2 d - g}$, a fact supporting HDA reaction with normal electronic demand (electronic transfer from the diene to the dienophile).

Regioselectivity appears to result from a balance between electronic and steric factors. Indeed, $\alpha$-acyl nitroso dienophiles $\mathbf{2 d - g}$ show comparable barriers for the proximal approach (1.5$\left.2.1 \mathrm{kcal} \cdot \mathrm{mol}^{-1}\right)$, but the distal selectivity varies from 3.8 to $7.6 \mathrm{kcal} \cdot \mathrm{mol}^{-1}$ as a function of the relative hindrance at $\mathrm{N}=\mathrm{O}$ 


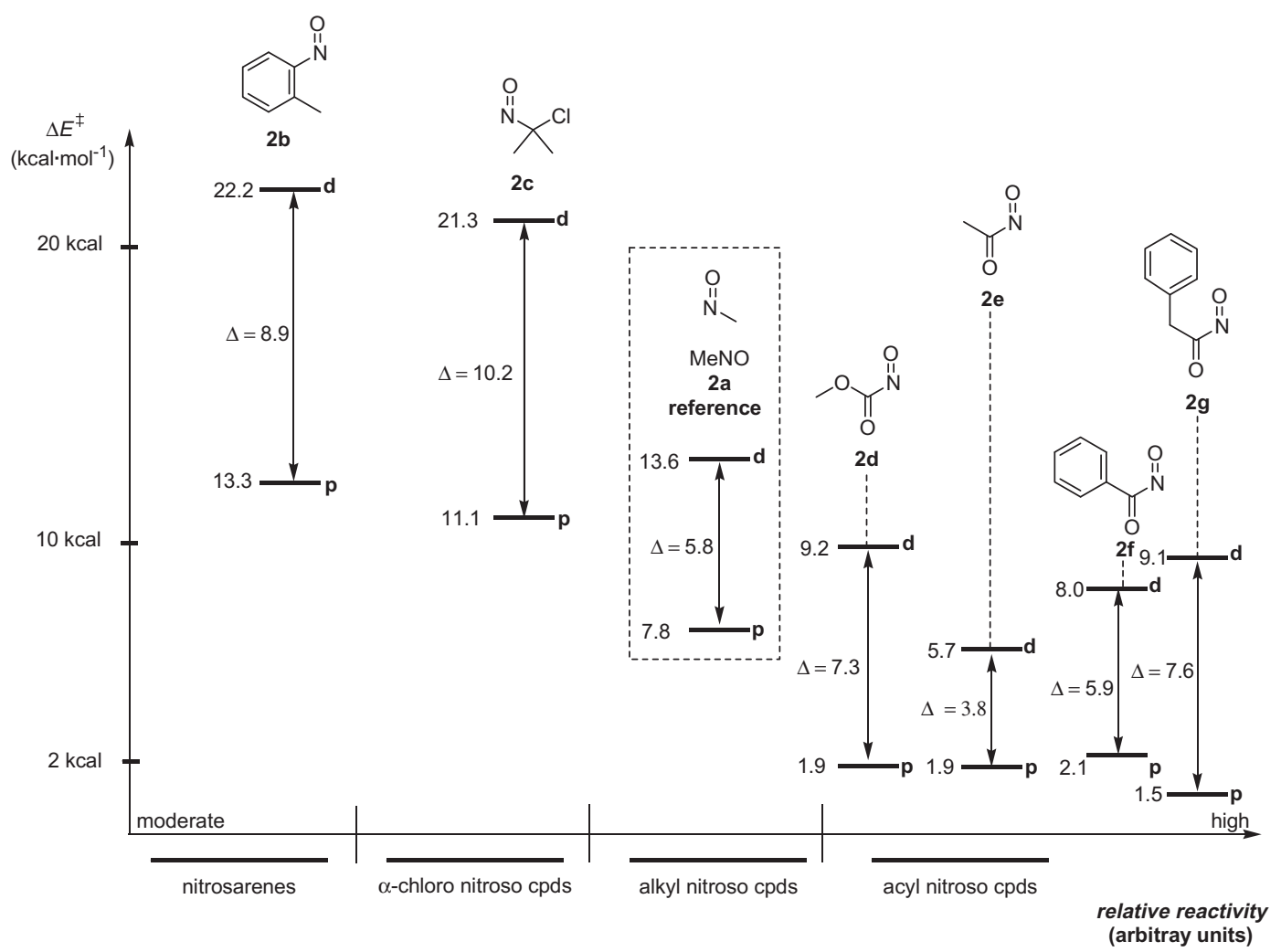

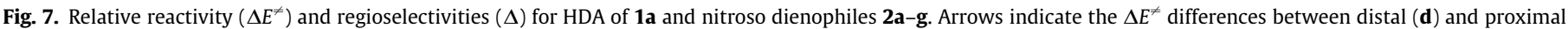
(p) pathways ( $\Delta E^{\neq}$is computed at $0 \mathrm{~K}$ fixed nuclei).

substitution, i.e. Phenylacetyl 2g > Benzoyl 2f > Methyloxycarbonyl 2d >> Acetyl 2e.

The B3LYP/6-31G** activation or reaction enthalpies and free Gibbs energies are listed in Table 4 for some representative examples. All these HDA reactions are exothermic reactions. Entries 1, 2 and 3 support that phosphonate incidence on both TS and product stabilization/destabilization is negligible. The reactions with methyl nitroso formate (2d) and acetyl nitroso (2e) are twice more exothermic than the reference MeNO, because the final product is an amide rather than and amine.

These cycloaddition partners have been also analyzed with reactivity indexes. The global static properties, i.e. the chemical potential $(\mu)$, the chemical hardness $(\eta)$ and the global electrophilicity $(\omega)$ are listed in Table 5 . Generally speaking, the chemical potentials of the selected dienes ( $\mu$ in the range -0.088 to $-0.154 \mathrm{au}$ ) are lower than those of the nitroso dienophiles ( $\mu$ in the range -0.154 to $0.185 \mathrm{au}$ ). Consequently, a charge transfer will occur from the diene to the dienophiles along the reaction coordinate. This fact supports the normal electronic demand of these Diels-Alder reactions and can be explained by the strong electrophilic character of these dienophiles. Indeed, all considered dienophiles have a global electrophilicity $(\omega)$ in the range $2.27-4.50 \mathrm{eV}$,

Table 4

Thermochemistry ( $\mathrm{kcal} \cdot \mathrm{mol}^{-1}$, computed at $298.15 \mathrm{~K}$ ) for a representative set of nitroso dienophiles and dienes.

\begin{tabular}{lllllll}
\hline Entry & Diene & R-NO & $\Delta H^{\neq}$ & $\Delta G^{\neq}$ & $\Delta H^{\circ}$ & $\Delta G^{\circ}$ \\
\hline 1 & Butadiene & $\mathbf{2 a}$ & 8.4 & 16.8 & -26.2 & -16.3 \\
2 & Piperylene & $\mathbf{2 a}$ & 8.6 & 14.4 & -22.6 & -14.9 \\
3 & $\mathbf{1 a}$ & $\mathbf{2 a}$ & 7.9 & 15.5 & -20.1 & -11.9 \\
4 & $\mathbf{1 a}$ & $\mathbf{2 b}$ & 13.5 & 21.0 & -10.8 & -23.1 \\
5 & $\mathbf{1 a}$ & $\mathbf{2 d}$ & 2.3 & 6.4 & -37.4 & -29.0 \\
6 & $\mathbf{1 a}$ & $\mathbf{2 e}$ & 1.6 & 6.2 & -41.4 & -30.0 \\
\hline
\end{tabular}

Table 5

Global static properties for the selected dienes and dienophiles.

\begin{tabular}{llll}
\hline & $\mu(\mathrm{au})$ & $\eta(\mathrm{au})$ & $\omega(\mathrm{eV})$ \\
\hline Dienes & & & \\
Butadiene & -0.127 & 0.208 & $\mathbf{1 . 0 5}$ \\
Piperylene & -0.119 & 0.203 & $\mathbf{0 . 9 4}$ \\
Cyclopentadiene & -0.111 & 0.201 & $\mathbf{0 . 8 3}$ \\
1a $\left(\mathrm{PO}(\mathrm{OEt})_{2}\right)$ & -0.150 & 0.193 & $\mathbf{1 . 5 8}$ \\
1b $\left(\mathrm{NMe}_{2}\right)$ & -0.088 & 0.179 & $\mathbf{0 . 5 8}$ \\
$\mathbf{1 c}\left(\mathrm{CO}_{2} \mathrm{Me}\right)$ & -0.154 & 0.180 & $\mathbf{1 . 7 9}$ \\
Dienophiles & & & \\
2a $(\mathrm{R}=\mathrm{Me})$ & -0.154 & 0.142 & $\mathbf{2 . 2 7}$ \\
2b $(\mathrm{R}=2-\mathrm{tol}))$ & -0.155 & 0.116 & $\mathbf{2 . 8 2}$ \\
2c $\left(\mathrm{R}=\mathrm{Me}{ }_{2} \mathrm{CCl}\right)$ & -0.166 & 0.143 & $\mathbf{2 . 6 1}$ \\
$\mathbf{2 d}\left(\mathrm{R}=\mathrm{CO}{ }_{2} \mathrm{Me}\right)$ & -0.183 & 0.122 & $\mathbf{3 . 7 3}$ \\
$\mathbf{2 e}(\mathrm{R}=\mathrm{Ac})$ & -0.185 & 0.103 & $\mathbf{4 . 5 0}$ \\
$\mathbf{2 f}(\mathrm{R}=\mathrm{Bz})$ & -0.171 & 0.117 & $\mathbf{3 . 3 8}$ \\
2g $(\mathrm{R}=\mathrm{BnCO})$ & -0.180 & 0.100 & $\mathbf{4 . 4 1}$ \\
\hline
\end{tabular}

i.e. strong electrophiles within the $\omega$ scale [20]. Table 5 shows that the electrophilicity of the nitroso compounds, and thus their reactivity, is strongly dependent on the substitution on the nitrogen atom (in good agreement with Fig. 7).

The presence of strong electron-withdrawing substituents on the nitroso dienophile drastically increases its electrophilicity (e.g. $\omega=4.5 \mathrm{eV}$ for $\mathbf{2 e}$, whereas this value drops to $2.27 \mathrm{eV}$ for 2a). The acyl nitroso derivatives $\mathbf{2 d}-\mathbf{g}$ are strong electrophiles and consequently very reactive species.

Also, the relatively low $\omega$ values calculated for butadiene, piperylene, cyclopentadiene and $\mathbf{1 b}$ indicate their lower electrophilic character in comparison with $\mathbf{1 a}$ and $\mathbf{1 c}$. The calculated $\omega$ values for butadiene $(\omega=1.05 \mathrm{eV}), \mathbf{1 a}(\omega=1.58 \mathrm{eV})$ and $\mathbf{1 c}(\omega=1.79 \mathrm{eV})$ show that the phosphonate moiety slowly increases the global electrophicity of the butadienyl moiety, in good agreement with 
previous observation [25]. The differences of electrophilicity between diene 1a and the selected dienophiles are in the range $\Delta \omega=0.69-2.92 \mathrm{eV}$, in good agreement with P-DA reactions $[19,20 \mathrm{~b}]$.

\section{Conclusion}

HDA cycloadditions of 1-diethoxyphosphonyl-1,3-butadiene (1a) with nitroso dienophiles $\mathbf{2 a - g}$ are exothermic reactions, proceeding via precocious polar cyclic transition states. These reactions belong to polar cycloadditions, with a one-step two-stage mechanism governed by a two-center interaction between the $C_{4}$ and $\mathrm{N}$ atoms. As a main feature of this mechanism, one can retain the highly asynchronous bond formation during the early stages of the TS rearrangement.

Additional observations concerning the effect of the phosphonate substituent onto butadienyl moiety have been collected. From the activation barrier point of view, the values obtained for the cycloaddition step are similar to those computed for piperylene or butadiene. Nevertheless, the study of the global electronic properties of the selected dienes has shown that the global static properties of diene 1a increased drastically in the electrophilicity scale to reach values comparable to diene 1c. Thus, formally, the polarizing nature of the phosphonate leads to an activation of the butadienyl moiety that is compensated by the steric hindrance of the diethoxyphosphonate moiety at the TS. Both this activation and the steric hindrance of the phosphonate ensure the proximal regioselectivity of the cycloadditions. Indeed, the discrimination towards the distal adduct is strengthened by a direct steric interaction between the $\mathrm{N}$-substituent of the nitroso and the phosphonate.

\section{Acknowledgments}

This work was supported by FRIA-F.N.R.S. (Fonds pour la Formation à la Recherche dans l'Industrie et dans l'Agriculture-Belgium, fellowship to J.-C.M.), and F.R.S.-FNRS by its support to access computational facilities (FRFC Project No. 2.4556.99 "Simulations numériques et traitement des données”). J.M.-B. and G.D. are senior research associates of F.R.S.-FNRS. The authors thank Prof. R. Robiette for solvent phase calculations using the Jaguar suite of programs and Dr. L.R. Domingo for stimulating discussions. Dr. C.S. Le Duff is acknowledged for the access to the Bruker Avance 500.

\section{Appendix A. Supplementary data}

Supplementary data associated with this article can be found, in the online version, at doi:10.1016/j.theochem.2010.08.004.

\section{References}

[1] F. Fringuelli, A. Taticchi, The Diels-Alder Reaction; John Wiley \& Sons, Ltd., 2002.

[2] (a) K.A. Jørgensen, Angew. Chem. Int. Edit. 39 (2000) 3558;

(b) H. Waldmann, Synthesis (1994) 535.

[3] H. Yamamoto, M. Kawasaki, Bull. Chem. Soc. Jpn. 80 (2007) 595.

[4] J.M. de los Santos, R. Ignacio, D. Aparicio, F. Palacios, J. Org. Chem. 72 (2007) 5202.

[5] (a) L.R. Domingo, E. Chamorro, P. Pérez, J. Org. Chem. 73 (2008) 4615; (b) G.L. Leach, K.N. Houk, J. Org. Chem. 66 (2001) 5192 (and references cited therein).
[6] D. Boger, M. Patel, F. Takusagawa, Ortho- and meta-regioisomers are named proximal and distal, according to the nomenclature initially introduced by Boger for HDA reactions involving nitroso dienophiles. J. Org. Chem. 50 (1985) 1911.

[7] (a) P. Wyatt, C. Villalonga-Barber, M. Motevalli, Tetrahedron Lett. 40 (1999) 149;

(b) K. Yamana, H. Nakano, Tetrahedron Lett. 37 (1996) 5963;

(c) S. Darling, F. Muralidharan, V. Muralidaharan, Tetrahedron Lett. 30 (1979) 2757;

(d) S. Darling, N. Subramanian, J. Org. Chem. 40 (1975) 2851;

(e) E. Claibourne, C. Griffin, W. Daniewski, J. Org. Chem. 35 (1970) 1691;

(f) C. Griffin, W. Daniewski, J. Org. Chem. 35 (1970) 1691;

(g) M. Pudovik, I. Konovalova, E. Ishmeava, Zh. Obshch. Biol. 33 (1963) 2509.

[8] (a) T. Leyssens, D. Peeters, Tetrahedron Lett. 49 (2008) 2095;

(b) T. Leyssens, D. Peeters, J. Mol. Struct. (Theochem) 673 (2004) 79;

(c) T. Leyssens, D. Peeters, J. Mol. Struct. (Theochem) 686 (2004) 71;

(d) R. Robiette, J. Marchand-Brynaert, D. Peeters, J. Mol. Struct. (Theochem) 587 (2002) 59.

[9] P. Savignac, B. Iorga, Modern Phosphonate Chemistry, CRC Press, 2003.

[10] (a) J.-C. Monbaliu, J. Marchand-Brynaert, Tetrahedron Lett. 49 (2008) 1839;

(b) A. Meekel, M. Resmini, U. Pandit, Chem. Commun. (1995) 571;

(c) G. Kresze, J. Firl, Tetrahedron Lett. (1965) 1163.

[11] (a) J.-C.Monbaliu, D. Peeters, J. Marchand-Brynaert, Tetrahedron Lett. 51 (2010) 1052;

(b) J.-C. Monbaliu, J. Marchand-Brynaert, Synthesis 11 (2009) 1876.

[12] A.D. Becke, J. Chem. Phys. 98 (1993) 5648. See also O. Wiest, D. Montiel, K. Houk, J. Phys. Chem. A 10 (1997) 8378.

[13] M.J. Frisch, G.W. Trucks, H.B. Schlegel, G.E. Scuseria, M.A. Robb, J.R. Cheeseman, V.G. Zakrzewski, J.J.A. Montgomery, R.E. Stratmann, J.C. Burant, S. Dapprich, J.M. Millam, A.D. Daniels, K.N. Kudin, M.C. Strain, O. Farkas, J. Tomasi, V. Barone, M. Cossi, R. Cammi, B. Mennucci, C. Pomelli, C. Adamo, S. Clifford, J. Ochterski, G.A. Petersson, P.Y. Ayala, Q. Cui, K. Morokuma, D.K. Malick, A.D. Rabuck, K. Raghavachari, J.B. Foresman, J. Cioslowski, J.V. Ortiz, A.G. Baboul, B.B. Stefanov, G. Liu, A. Liashenko, P. Piskorz, I. Komaromi, R. Gomperts, R.L. Martin, D.J. Fox, T. Keith, M.A. Al-Laham, C.Y Peng, A. Nanayakkara, C. Gonzalez, M. Challacombe, P.M.W. Gill, B. Johnson, W. Chen, M.W. Wong, J.L. Andres, C. Gonzalez, M. Head-Gordon, E.S. Replogle, J.A. Pople, Gaussian 98, Revision A, Gaussian, Inc., Pittsburgh PA, 1998.

[14] V.A.Rassolov, M.A. Ratner, J.A. Pople, P.C. Redfern, L.A. Curtiss, J. Comp. Chem. 22 (2001) 976.

[15] (a) C. Gonzalez, H.B. Schlegel, J. Chem. Phys. 94 (1990) 5523;

(b) C. Gonzalez, H.B. Schlegel, J. Chem. Phys. 4 (1989) 2154.

[16] (a) A.E. Reed, F. Weinstock, F. Weinhold, J. Chem. Phys. 83 (1985) 735;

(b) A.E. Reed, F. Weinhold, J. Chem. Phys. 78 (1983) 4066;

(c) J.P. Foster, F. Weinhold, J. Am. Chem. Soc. 102 (1980) 7211;

(d) S. Boys, Quantum Theory of Atoms Molecules and the Solid State, Academic Press, New York, 1966;

(e) S. Boys, Rev. Mod. Phys. 32 (1960) 296.

[17] (a) M.M. Heredia, M. Lorono, T. Cordova, G. Chuchani, J. Mol. Struct. (Theochem) 770 (2006) 131;

(b) B. Lecea, A. Arrieta, G. Roa, J.M. Ugalde, F.P. Cossio, J. Am. Chem. Soc. 166 (1994) 9613;

(c) A. Moyano, M.A. Pericàs, E. Valenti, J. Org. Chem. 54 (1989) 573;

(d) A.E. Reed, F. Curtiss, F. Weinhold, Chem. Rev. 88 (1988) 899;

(e) K.B. Wiberg, Tetrahedron 24 (1968) 1083.

[18] D.H. Hess, O.J. Jones, K.N. Houk, Adv. Synth. Catal. 348 (2006) 2337.

[19] (a) L.R. Domingo, J.A. Sáez, P. Pérez, Chem. Phys. Lett. 438 (2007) 341;

(b) L.R. Domingo, M.T. Picher, P. Arroyo, Eur. J. Org. Chem. (2006) 2570;

(c) L.R. Domingo, M.J. Aurell, P. Pérez, R. Contreras, J. Phys. Chem. A 106 (2002) 6871 .

[20] (a) L.R. Domingo, J.A. Sàez, Org. Biomol. Chem. 7 (2009) 3576;

(b) L.R. Domingo, J.A. Sàez, R.J. Zaragozà, M. Arnò, J. Org. Chem. 73 (2008) 8791 ;

(c) L.R. Domingo, M.J. Aurell, P. Pérez, R. Contreras, J. Org. Chem. 68 (2002) 3884;

(d) L.R. Domingo, M.J. Aurell, P. Pérez, R. Contreras, Tetrahedron 58 (2002) 4417.

[21] Jaguar suite of programs, version 6.5, Schrödinger, LLC, New York, NY, 2005.

[22] (a) S. Kozmin, M. Green, V. Rawal, J. Org. Chem. 64 (1999) 8045;

(b) C. Reichardt, Solvents and Solvent Effects in Organic Chemistry, VCH, Weinheim, 1988.

[23] J. Streith, A. Defoin, Synthesis (1994) 1107.

[24] J.-C. Monbaliu, J. Marchand-Brynaert, D. Peeters, Tetrahedron Lett. 50 (2009) 2555 (and references cited therein).

[25] R. Robiette, N. Defacqz, D. Peeters, J. Marchand-Brynaert, Curr. Org. Synth. 2 (2005) 453 (and references cited therein). 